\title{
Trends in Educational Technology: What Facebook, Twitter, and Scopus Can Tell us about Current Research and Practice
}

\author{
Royce Kimmons $^{1} \cdot$ Joshua Rosenberg $^{2} \cdot$ Bohdana Allman $^{1}$
}

Accepted: 3 February 2021 / Published online: 24 February 2021

(C) Association for Educational Communications \& Technology 2021

\begin{abstract}
Using large-scale, public data sources, this editorial provides a high-level description of educational technology trends leading up to and encompassing the year 2020. Data sources included (a) 17.9 million Facebook page posts by K-12 educational institutions in the U.S., (b) 131,760 tweets to the \#EdTech hashtag on Twitter, and (c) 29,636 educational technology articles in the Scopus database. We provide a variety of descriptive results in the form of participation frequency charts, keyword matches, URL domain link counts, co-occurring hashtags, tweet text word trees, and common word and bigram frequencies. Results from the analysis of Facebook posts indicated that (a) schools increasingly used the platform over time, (b) the pandemic increased frequency (but not the nature) of use, (c) schools are progressively sharing more media, information, and tools, and (d) some of these tools align with trends identified by Weller (2020) while others do not. Analysis of tweets indicated that (a) discussions in 2020 revolved around "remote learning" and related topics, (b) this emphasis shifted or morphed into "elearning" and "online learning" as the year progressed, (c) shared posts were primarily informational or media-based, and (d) the space was heavily directed by a relatively small group of Superusers. Last, analysis of articles in Scopus indicated that (a) online learning is historically the most-researched topic in the field, (b) the past decade reflects a shift to more "open" and "social" topics, and (c) there seems to be a lag or disconnect between emergent high-interest technologies and research. Taken together, we conclude that these results show the field's preparation for addressing many challenges of 2020, but propose that, moving forward, we would be better served by embracing greater philosophical plurality and better addressing key issues, including equity and practicality.
\end{abstract}

Indelibly marked by COVID-19, 2020 witnessed many shifts in educational technology policies, practices, and attitudes as institutions and individuals scrambled to respond to the pandemic. Practically overnight, schools and universities across the world made cataclysmic shifts to emergency remote teaching (Hodges et al. 2020), using various technologies like Zoom, Google Meet, Google Docs, and Nearpod to enable teaching at a safe distance. New phrases entered our

Royce Kimmons

roycekimmons@gmail.com

Joshua Rosenberg

jmrosenberg@utk.edu

Bohdana Allman

bohdana.allman@byu.edu

1 Brigham Young University, 150J MCKB, Provo, UT 84602, USA

2 University of Tennessee, Knoxville, 420 Claxton, 1122 Volunteer Blvd, Knoxville, TN 37996, USA vernacular to articulate our experiences and struggles - such as "lockdown," "crisis teaching," and "Zoom fatigue"- and though the novel virus introduced many new challenges, it also served as an accelerant of many existing trends and challenges facing the field. This is especially noteworthy as it casts attention upon insidious tensions within our research and practices involving inequity, scalability, sustainability, privacy, and practicality (Dwivedi et al. 2020; Williamson et al. 2020).

Exactly how this past year shaped educational technology and its future as a field is a complex question; nevertheless, in this editorial, we will continue our ongoing efforts to use large-scale public data sources to illustrate emergent trends and trajectories (Kimmons 2020) and articulate some takeaways that should guide us in moving forward. Building off of previous studies that have analyzed many of these data sources for several years (Kimmons et al. 2019; Trust et al. 2020), we will focus the current analysis on three data sources: (1) posts on U.S. school and district Facebook pages $(n=17.9$ million posts by 15,728 institutions), (2) original Twitter posts 
with the \#EdTech hashtag ( $n=131,760$ tweets by 24,561 users), and (3) research article titles and abstracts provided by the Scopus API for top educational technology journals ( $n=29,636$ articles from 34 journals).

Such broad-scope analyses are essential for the field as they allow us to see the big picture of what has been happening over time, enable us to step out of our insulated experiences as singular researchers and practitioners, and help us to consider where our collective attentions are focused and where missing links might exist (Bodily et al. 2019; Kimmons 2020; Lin et al. 2019). These analyses rely wholly upon public data sources available through the internet (Kimmons and Veletsianos 2018), and though not exhaustive or representative of all contexts, they open up a window to view current trends in their complexity and from different angles, thereby offering implications for research and practice and suggesting ongoing course corrections into the future.

\section{K-12 Facebook Groups}

Facebook is a social networking platform that is actively used by many individuals, schools, and districts throughout the U.S. and worldwide. We previously estimated that $44 \%$ of schools in the U.S. use the service (Kimmons et al. 2019), and it is estimated currently that $69 \%$ of adults in the U.S. also use Facebook (Perrin and Anderson 2019). Such ubiquity means that schools can use Facebook as a low-stakes, highimpact communication medium to share information and engage with many parents and community members quickly.

Starting with identifiers provided by the National Center for Education Statistics (2019), we accessed the contents of the homepage for each U.S. school district and public school and identified all of the external links from these pages using the R statistical software (R Core Team 2021). Among these links, we selected those linking to Facebook pages of any kind and identified 7744 unique districts and 7984 schools $^{1}$ with pages (for a total of 15,728 unique K-12 educational institutions). These were associated with a total of 13,127 unique Facebook pages, as some districts and schools linked to the same page. We then applied for and gained access to the CrowdTangle platform (CrowdTangle Team 2020), which is owned by Facebook and provides access to the posts of public pages and groups on Facebook to academics and journalists, and uploaded all of the Facebook links we identified. Finally, we used the historical access feature to download all of the posts from the identified pages for 2005-2020, which resulted in downloading the data for $17,979,285$ posts, including their

\footnotetext{
${ }^{1}$ These school pages were those that remained after removing pages linked from schools to pages to which districts also linked; we reasoned that these were likely to be district-level pages.
}

date and time, message (text) content, and the number of reactions and comments for each post (see Fig. 1).

Analyses revealed significant variation between and within years, with a general pattern of more posts in each subsequent year and more posts in the Spring and Fall relative to the summer (and to the time coinciding with the winter holidays). This trend may represent increased technology tool use for school-home communication within the years and a typical pattern of school activities and related communication across the U.S. academic year. While we cannot say based on this figure alone, the events of 2020 may suggest interpretation for the pattern found in school Facebook activity across 2020. A great deal of activity in Spring 2020 is possibly due to districts and schools responding to the pandemic; then in the later part of the year, the lower activity than expected may have resulted from fewer posts about typical topics and activities (i.e., athletics) that occurred at lower rates due to pandemic restrictions.

To understand trends in posts about educational technology-related topics over time, we considered the technologies identified by Weller (2020) in his history of the past 25 years of educational technology. From Weller's list, we searched for keywords associated with each technology (e.g., "LMS" for "learning management system") in posts and organized results by year to see how mentions of technologies aligned with Weller's timeline (see Table 1).

Our results - presented by year - indicate that a number of topics were posted about relatively frequently, including videos, blogs, Twitter and social media, the web, and e-learning, each of which was posted more than 10,000 times, with videos and blogs included in more than 300,000 and 200,000 posts, respectively. Wikis and learning management systems were also referenced in many posts, with each being posted about more than 1000 times. While it may be that reference to some of these topics was in the context of using a feature of the Facebook platform itself (e.g., sharing a video), others, such as e-learning, are probably independent of any functionality of Facebook, and, even knowing that districts and schools posted more than 100,000 videos in 2020 (relative to less than 10,000 in the period from 2010 to 2012) suggests marked increase in use and interest in the technology. Conversely, many topics that one might expect to be posted about with some degree of frequency were included only infrequently (e.g., digital badges, open textbooks), while some were posted relatively infrequently, but perhaps more than one would expect given that these were posts by Facebook accounts associated strictly with districts and schools (e.g., artificial intelligence, second life, and virtual worlds).

Next, we focused on the domains of links that districts and schools posted. We chose to focus on the most recent three years of activity (2018-2020, $n=9,868,611$ posts) and used the urltools R package (Keyes et al. 2019) to extract the domain (e.g., dreambox.com) from the URL, which was often 
Fig. 1 School Facebook Group Posting Activity by Month and Year

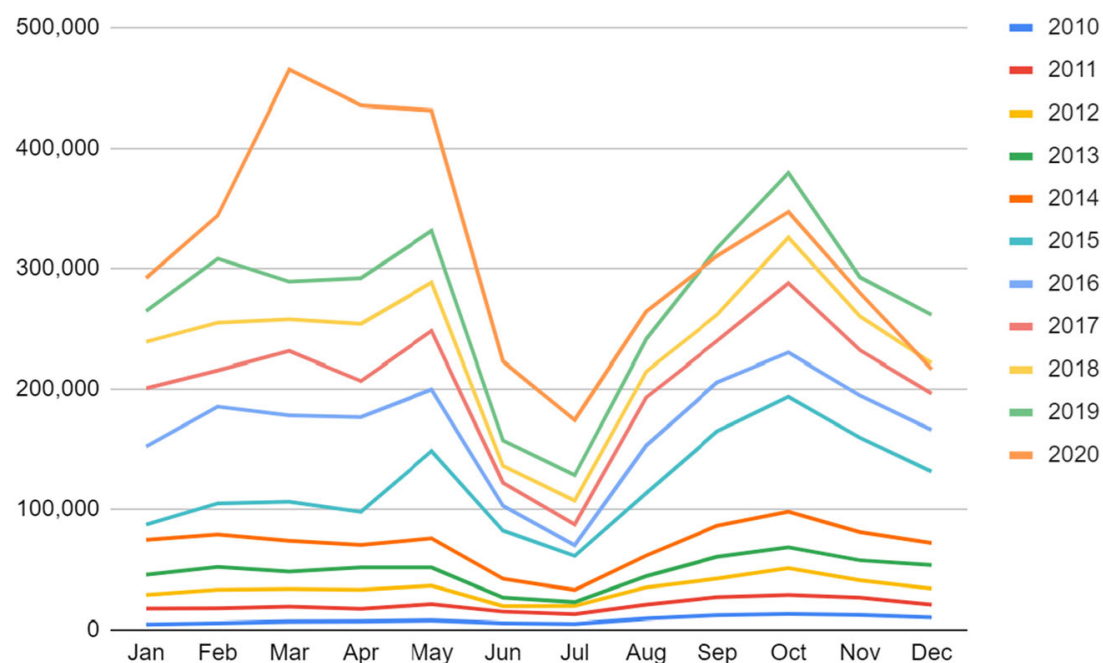

directing the reader to a specific page (or resource) on a larger domain. Finally, we aggregated the data at the district and school level and examined whether the district or school posted a link to a specific domain in 2018, 2019, and
2020. We also manually removed links to URL shorteners (e.g., bit.ly, t.co) and other social media platforms, inferring that many of these were crosspostings between or across platforms. Links from these

Table 1 Keyword Matches in K-12 Facebook Posts for Weller's (2020) Identified Technologies and Topics

\begin{tabular}{|c|c|c|c|c|c|c|c|c|c|c|c|c|}
\hline Topic & 2010 & 2011 & 2012 & 2013 & 2014 & 2015 & 2016 & 2017 & 2018 & 2019 & 2020 & Total \\
\hline 1994: Bulletin Board Systems & 0 & 0 & 0 & 0 & 0 & 0 & 0 & 2 & 0 & 0 & 0 & 2 \\
\hline 1995: The Web & 367 & 838 & 1549 & 2229 & 3019 & 4203 & 4350 & 4407 & 4565 & 4953 & 12,269 & 42,749 \\
\hline 1996: Computer-Mediated Communication & 0 & 0 & 0 & 0 & 1 & 0 & 0 & 0 & 0 & 0 & 0 & 1 \\
\hline 1997: Constructivism & 0 & 0 & 2 & 0 & 0 & 0 & 3 & 3 & 13 & 1 & 3 & 25 \\
\hline 1998: Wikis & 29 & 64 & 139 & 164 & 255 & 351 & 410 & 474 & 451 & 515 & 736 & 3588 \\
\hline 1999: E-Learning & 31 & 54 & 104 & 132 & 175 & 236 & 387 & 347 & 575 & 834 & 8362 & 11,237 \\
\hline 2000: Learning Objects & 0 & 2 & 8 & 9 & 19 & 32 & 45 & 42 & 80 & 81 & 77 & 395 \\
\hline 2001: E-Learning Standards & 0 & 0 & 0 & 0 & 0 & 0 & 0 & 0 & 0 & 0 & 0 & 0 \\
\hline 2002: Learning Management Systems & 0 & 4 & 12 & 14 & 19 & 49 & 60 & 69 & 70 & 79 & 719 & 1095 \\
\hline 2003: Blogs & 2044 & 4349 & 7601 & 10,913 & 14,604 & 21,972 & 26,903 & 29,337 & 30,023 & 33,583 & 35,469 & 216,798 \\
\hline 2004: Open Educational Resources & 0 & 1 & 1 & 0 & 1 & 5 & 7 & 10 & 5 & 5 & 4 & 39 \\
\hline 2005: Video & 2309 & 4417 & 7658 & 11,178 & 16,788 & 25,138 & 31,361 & 39,267 & 42,677 & 41,493 & 116,985 & 339,271 \\
\hline 2006: Web 2.0 & 5 & 16 & 13 & 6 & 3 & 3 & 7 & 5 & 2 & 1 & 1 & 62 \\
\hline 2007: Second Life and Virtual Worlds & 2 & 1 & 3 & 5 & 8 & 15 & 15 & 33 & 27 & 32 & 301 & 442 \\
\hline 2008: E-Portfolios & 0 & 1 & 2 & 6 & 10 & 3 & 10 & 6 & 6 & 7 & 6 & 57 \\
\hline 2009: Twitter and Social Media & 104 & 225 & 440 & 829 & 1512 & 3095 & 4646 & 5853 & 7989 & 9266 & 20,459 & 54,418 \\
\hline 2010: Connectivism & 0 & 0 & 0 & 0 & 0 & 0 & 0 & 0 & 0 & 0 & 0 & 0 \\
\hline 2011: Personal Learning Environments & 0 & 0 & 0 & 1 & 5 & 0 & 1 & 1 & 1 & 0 & 0 & 9 \\
\hline 2012: Massive Open Online Courses & 0 & 0 & 1 & 8 & 5 & 0 & 0 & 1 & 0 & 1 & 1 & 17 \\
\hline 2013: Open Textbooks & 0 & 0 & 0 & 0 & 0 & 0 & 1 & 0 & 0 & 4 & 1 & 6 \\
\hline 2014: Learning Analytics & 0 & 0 & 1 & 2 & 1 & 0 & 4 & 4 & 1 & 0 & 3 & 16 \\
\hline 2015: Digital Badges & 0 & 3 & 0 & 2 & 6 & 8 & 17 & 19 & 18 & 35 & 29 & 137 \\
\hline 2016: Artificial Intelligence & 0 & 2 & 2 & 2 & 2 & 11 & 19 & 47 & 82 & 119 & 98 & 384 \\
\hline 2017: Blockchain & 0 & 0 & 0 & 0 & 0 & 0 & 0 & 6 & 29 & 14 & 12 & 61 \\
\hline Total & 4891 & 9977 & 17,536 & 25,500 & 36,433 & 55,121 & 68,246 & 79,933 & 86,614 & 91,023 & 195,535 & 670,809 \\
\hline
\end{tabular}


pages, we inferred, could speak to what resources, tools, and platforms districts and schools both communicated about and therefore used in a way that was not otherwise practical to determine at such a scale. Organizing these links by domain and year allowed us to determine the most-shared external resources over the course of the three years (see Table 2). Note that this table represents the number of unique institutions sharing one or more links for each of the analyzed years (rather than the number of posts including a link or links to the domain).

Results indicated that Google-owned domains (YouTube, Docs, Search, Drive, Sites, and Accounts) represented the top four most-linked-to domains for all three years (see Table 1). This is not surprising as these domains support school and district communication by finding, sharing, and managing documents, videos, and other files. Scheduling and survey tools (such as Survey Monkey, EventBrite, and Signup Genius) were also commonly posted each year, as was the communication tool Smore, a tool for education-related products (Scholastic). Notably, Zoom was the fifth most-shared domain in 2020 but was not among the top- 25 in 2018 or 2019. Also, notably, Center for Disease Control links were common in 2020 but were much less common in previous years.

These results support previous studies on links provided on K-12 school websites (Kimmons 2020;
Kimmons et al. 2019) and show that schools use Facebook as a way of coordinating various efforts and disseminating information from a variety of sources primarily for communication purposes to support school management processes and typically utilize free generic, non-pedagogical tools. Furthermore, though 2020 saw a greater emphasis on a few specific tools (such as Zoom) and information sources (such as the CDC) as well as increased activity overall, the general nature of the activity did not change much, with most tools that were being used in previous years also being used in 2020 and in similar orders of frequency. Furthermore, the frequency of communication clearly represented the schools and districts' responses to communication and other needs across a typical academic year (years 2010-2019) as well as showed clear evidence of rapid responsiveness to exceptional events (2020).

From this analysis of school Facebook pages, we conclude that (a) schools are increasingly using the social medium as a means of communication, (b) the degree of use generally increased in conjunction with the pandemic but the type of use did not meaningfully change, (c) schools are increasingly sharing more media, information, and productivity tools (e.g., forms, scheduling) as time progresses, and (d) some of these activities align with Weller's historical observations while others do not.
Table 2 Top 15 Most Frequently Linked Domains by U.S. K-12 Educational Institutions' Facebook Groups

\begin{tabular}{|c|c|c|c|c|c|}
\hline \multicolumn{2}{|l|}{2018} & \multicolumn{2}{|l|}{2019} & \multicolumn{2}{|l|}{2020} \\
\hline Domain & $\mathrm{n}$ & Domain & $\mathrm{n}$ & Domain & $\mathrm{n}$ \\
\hline youtube.com & 4787 & youtube.com & 5080 & youtube.com & 10,217 \\
\hline docs.google.com & 3844 & docs.google.com & 4516 & docs.google.com & 10,002 \\
\hline google.com & 2564 & google.com & 3175 & google.com & 9818 \\
\hline drive.google.com & 1705 & drive.google.com & 2058 & drive.google.com & 5582 \\
\hline surveymonkey.com & 1371 & surveymonkey.com & 1512 & zoom.us & 4528 \\
\hline signupgenius.com & 1129 & signupgenius.com & 1431 & accounts.google.com & 3711 \\
\hline eventbrite.com & 1081 & eventbrite.com & 1315 & sites.google.com & 3458 \\
\hline vimeo.com & 920 & $\begin{array}{l}\text { bookfairs.scholastic. } \\
\text { com }\end{array}$ & 1017 & cdc.gov & 2462 \\
\hline $\begin{array}{l}\text { bookfairs.scholastic. } \\
\text { com }\end{array}$ & 718 & vimeo.com & 983 & surveymonkey.com & 2237 \\
\hline sites.google.com & 709 & smore.com & 870 & $\begin{array}{l}\text { bookfairs.scholastic. } \\
\text { com }\end{array}$ & 1817 \\
\hline accounts.google.com & 650 & sites.google.com & 863 & smore.com & 1783 \\
\hline smore.com & 601 & accounts.google.com & 781 & vimeo.com & 1635 \\
\hline gofundme.com & 570 & applitrack.com & 642 & 2020census.gov & 1449 \\
\hline applitrack.com & 500 & mailchi.mp & 454 & signupgenius.com & 1405 \\
\hline smile.amazon.com & 490 & gofundme.com & 447 & eventbrite.com & 1225 \\
\hline
\end{tabular}

Note. The number of institutions sharing one or more links in 2017 was 12,927, with 13,719 in 2019 and 14,982 in 2020. The number of institutions sharing one or more links can aid in the interpretation of the above frequencies; for example, the 10,217 institutions sharing links to Google Docs in 2020 made up $66.7 \%$ of districts sharing one or more links 


\section{\#EdTech on Twitter}

Twitter is also a popular social networking platform that is estimated to be used by $22 \%$ of adults (Perrin and Anderson 2019) and $40 \%$ of schools in the U.S. (Kimmons et al. 2019). Like Facebook, Twitter is generally a public platform that schools use to broadcast information to their communities (Kimmons et al. 2018), but it also allows for discussions surrounding various topics to emerge organically via hashtags as users openly participate in "affinity spaces" with others who are interested in similar topics (Carpenter et al. 2019; Gee 2004; Trust et al. 2016, 2020). In our field, \#EdTech has emerged as a popular affinity space on Twitter for schools, teachers, businesses, and thought leaders to discuss matters of interest and to share resources freely with one another. To post to the hashtag, users do not need to be accepted to a group or meet any other vetting criterion, which means that the space is an open one and reflects diverse perspectives, opinions, and lives of those who are merely interested in participating in the broad \#EdTech conversation.

To identify trending topics, we used a custom PHP/ MySQL collector to constantly query the Twitter Search API from February to December 2020, collecting all English-language original tweets using the hashtag \#EdTech. Because the collection mechanism relied on persistent monitoring of the Twitter API, there were some instances of lapses or errors in the data collection. Overall, however, collected tweets generally represented most weeks of the studied year with the only major gaps occurring before March. The final dataset represented tweets from 311 out of the 365 days in 2020 (or $85.2 \%$ of days) with an average of 424 tweets per day ( $S D=175.4$ ) by 289 distinct users per day $(S D=120.8)$.

This provided a dataset of 131,760 original tweets representing 24,561 distinct users. We calculated descriptive statistics of results and found that users exhibited a highly positive skew in their posting activities. This behavior was expected (based on previous studies done on Twitter, such as Veletsianos and Kimmons 2016) and led us to follow Van Mierlo's (2014) 90-9-1 principle to classify users into relative activity groups as either: Superusers (top $1 \%$ posting content), Contributors (next 9\% contributing content), or Lurkers (the remaining 90\%; see also Mockus et al. 2002). Results indicated that Superusers posted almost as much as the remaining $99 \%$ of users (representing $45.9 \%$ of all tweets), out-tweeting Contributors at a rate of 16-to-1 and Lurkers at a rate of 144-to-1 (see Table 3).

We then extracted co-occurring hashtags from tweets, which consisted of additional hashtags that were included in \#EdTech tweets, revealing the thematic categories, topics, or descriptors that authors assigned to their tweets or showing us what they were sharing or thinking in relation to their educational technology tweets. Table 4 provides the top 15 most common co-occurring hashtags, with \#education, \#edchat, and \#remotelearning being the three most common. Of these, \#education and \#edchat are expected to be consistent across years given the general nature of the \#education hashtag and the prevalence of \#edchat as an affinity space closely related to \#edtech. Notably, however, ranked hashtags 3 through 6 were all related to remote, online, or distance learning, which was certainly influenced by the onset of \#covid19 (ranked as \#7 in the list) early in the year. To illustrate this relationship, \#remotelearning tweets spiked in April with \#covid[related] tweets (outperforming the other related hashtags) and then dwindled significantly by September, suggesting that as the COVID-19 pandemic continued, \#remotelearning information, resources, and activities became more normalized or replaced (at least in name) by \#elearning and \#onlinelearning (see Fig. 2).

We then parsed tweet texts into individual words and bigrams (i.e., two words in succession, such as "online learning"), as we expected these to augment the co-occurring hashtag data with more implicit topics that users might not have felt merited topical tagging (e.g., "Google", "privacy"). These were constructed into word trees around the two most common words - "education" and "learning"- to reveal how common words were used in relation to one another with relative size differences representing frequencies (see Figs. 3 and 4). Of these, common phrases like "higher education," "online education," "online learning," and "distance learning" were expectedly found, but so too were more unique and unexpected bigrams, such as "democratise education," "learning group," and "emotional learning," revealing specific topics important to \#EdTech tweeters. Furthermore, to show the prevalence of K-12 vs. higher education interaction in this space, a keyword search revealed that many more tweets referenced a variant of "K-12" $(n=3892)$ than did "higher" $(n=$ 2997), suggesting the K-12 community was slightly dominant.

Finally, we collected all referenced hyperlinks to determine what external resources authors linked to in their tweets. Overall, $92.1 \%$ of all tweets included a link of some kind (including links to images), revealing that the \#EdTech hashtag was heavily used for sharing resources or images and organizing discussion around these resources rather than simply stating ideas, beliefs, or attitudes (as might be visible with other broad hashtags like \#education). Of these, links to the news site EdSurge were the most universally shared by community members, followed by YouTube videos and Paper.li content (see Table 5). Other sites that made the list included influencer websites (like Shake Up Learning), education news sites (like EdSurge, EdTechMagazine, and Edutopia), social media (like LinkedIn and Instagram), generic news sites (like Forbes and New York Times), tools (like Google Docs), and others. Some of these results were similar to those found on Facebook (e.g., the prevalence of 
Table 3 Descriptives for \#EdTech User Activity Groups

\begin{tabular}{lllll}
\hline Metric & Overall & Superusers & Contributors & Lurkers \\
\hline Tweets & 131,760 & $60,427(45.9 \%)$ & $34,740(26.4 \%)$ & $36,593(27.8 \%)$ \\
Users & 24,561 & 246 & 2210 & 22,105 \\
Mean tweets per user & 5.4 & 245.6 & 15.7 & 1.7 \\
SD tweets per user & 53.6 & 475.6 & 10.5 & 1.2 \\
\hline
\end{tabular}

YouTube), but the preponderance of news sites suggests that the \#EdTech affinity space was much more focused on sharing information and news while the Facebook pages were being used more for communication and collaboration purposes.

From these Twitter \#EdTech results, we conclude that (a) COVID-19 both explicitly and implicitly shaped the \#EdTech affinity space in 2020 with most discussions revolving around remote, online, distance, and blended learning, (b) "remote learning" emerged in conjunction with COVID-19 in April but then became normalized as "elearning" or "online learning" shortly thereafter, (c) shared resources are heavily informational (e.g., news sites) or media-based (e.g., video sharing), and (d) though the \#EdTech affinity space is broad and involves many people, trends are heavily directed by a relatively small group of Superusers.

\section{Research Topics}

And finally, to see how these trends connected to patterns in the educational technology research literature, we also extracted all article titles and abstracts from the Elsevier article search database, using the Scopus Search API (Elsevier, n.d.), for many of the top educational technology journals. We identified journals by referring to Google Scholar (n.d.) h-indices for journals organized in the "Educational Technology" category and further supplemented this by a popular list of educational technology journals by Perkins and Lowenthal (n.d.), covering the years 2000 to 2020. In total, our list included 34 journals with 27,219 articles with titles and abstracts (or 29,636 articles with only titles), representing 1296 articles per year $(\mathrm{SD}=881.9)$ and 801 articles per journal $(\mathrm{SD}=$ 1059.2).

Querying the Scopus API, we used a series of cURL commands using PHP and analyzed and stored title and abstract word frequency results in a relational MySQL database, organized by journal identifier and year of publication. We then considered word and word-pair (bigram) frequencies in both article titles and abstracts to better understand topics for each year. To improve the accuracy of word counts, we used PHP to remove stopwords (e.g., "a," "an," "the"), numbers, capitalization, and punctuation and to reduce words to their stems (e.g., converting "learn," "learns," and "learning" to "learn*").

The most common keywords in titles included generic keyword stems like "learn," "education," "teach," and "technology" but also included specific modalities or technologies like "online," "computer," etc. (see Table 6). "Student*" was the
Table 4 Top 15 Most Common Co-occurring Hashtags with \#EdTech in 2020

\begin{tabular}{lllll}
\hline Hashtag & Total Users & Percent of Users & Total Tweets & Percent of Tweets \\
\hline \#education & 2726 & $11.1 \%$ & 12,013 & $9.1 \%$ \\
\#edchat & 1765 & $7.2 \%$ & 19,474 & $14.8 \%$ \\
\#remotelearning & 1618 & $6.6 \%$ & 3959 & $3.0 \%$ \\
\#onlinelearning & 1065 & $4.3 \%$ & 3141 & $2.4 \%$ \\
\#elearning & 1044 & $4.3 \%$ & 5997 & $4.6 \%$ \\
\#distancelearning & 873 & $3.6 \%$ & 2017 & $1.5 \%$ \\
\#covid19 & 795 & $3.2 \%$ & 1665 & $1.3 \%$ \\
\#edtechchat & 781 & $3.2 \%$ & 4650 & $3.5 \%$ \\
\#learning & 734 & $3.0 \%$ & 1861 & $1.4 \%$ \\
\#highered & 670 & $2.7 \%$ & 2050 & $1.6 \%$ \\
\#teachers & 590 & $2.4 \%$ & 1846 & $1.4 \%$ \\
\#k12 & 576 & $2.3 \%$ & 2759 & $2.1 \%$ \\
\#stem & 550 & $2.2 \%$ & 1699 & $1.3 \%$ \\
\#ai & 549 & $2.2 \%$ & 1229 & $0.9 \%$ \\
\#technology & 508 & $2.1 \%$ & 1028 & $0.8 \%$ \\
\hline
\end{tabular}




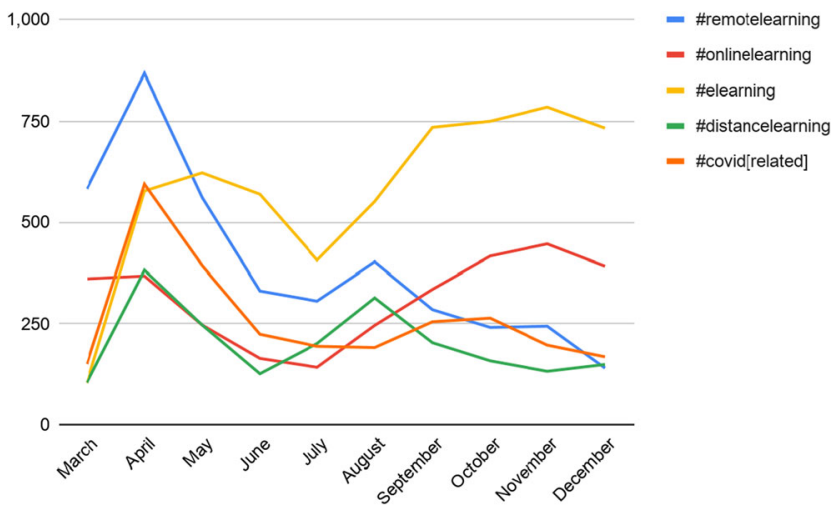

Fig. 2 Frequency of Five Hashtags Related to Remote and Online Learning and COVID-19 by Month

second most-common word and (combined with "learner" being grouped with the top word "learn*") suggests the literature is largely student- or learner-centric in this regard. However, without context, it was difficult to glean much from single terms, because each could be used in diverse settings to reflect various meanings (such as "social" being used for a technology like "social media," an outcome like "social-emotional health," a classroom strategy like "social interaction," etc.). Title bigrams were a bit more helpful in this regard and revealed that titles included common references to (a) educational settings, such as "higher education" or "high school," (b) modalities, such as "learning environment" or "online learning," (c) pedagogical approaches, such as "project/problem/game-based learning" or "collaborative learning," (d) specific technologies, such as "social network" or "social media," (e) research subjects, such as "school student" or "preservice [teachers]," (f) learning outcomes, such as "problem solving" or "language learning," or (g) research methods, such as "student perception" or "learning analytics" (see Table 7).

Identical analyses of abstracts revealed similar results, with generic words like "learn," "student," "result," and "education" being the most common. Removing common distractors

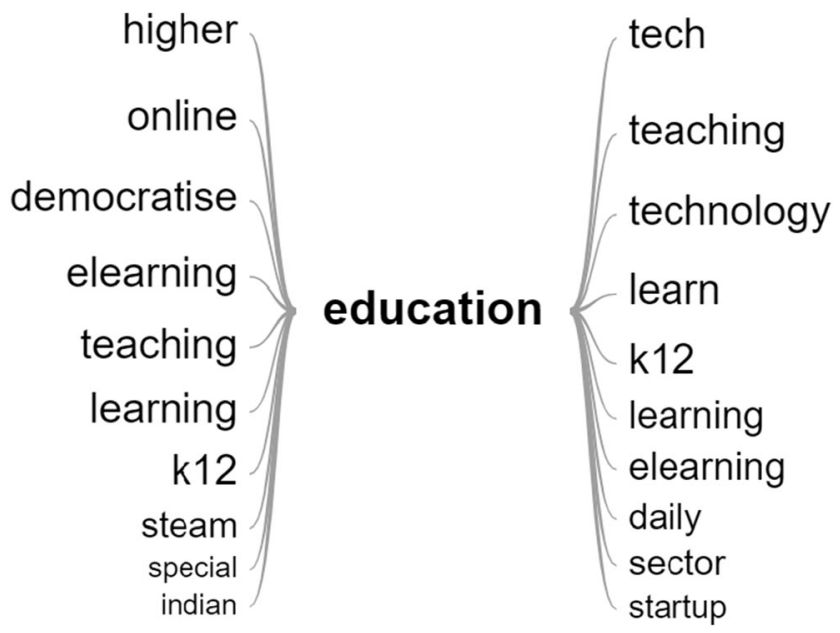

Fig. 3 Tweet Text Word Tree for "Education"

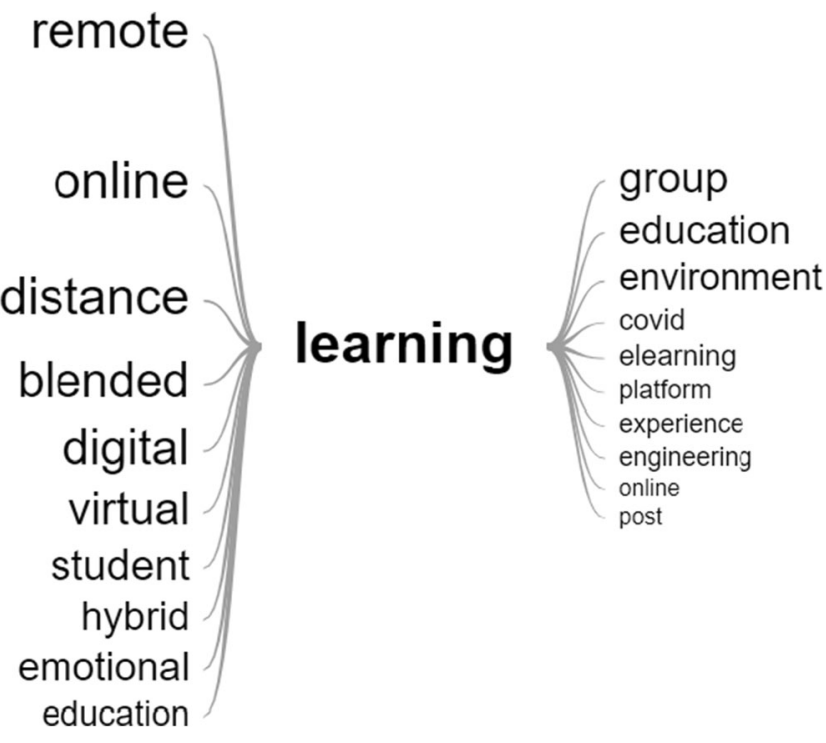

Fig. 4 Tweet Text Word Tree for "Learning"

like "results show," bigrams were again more instructive and yielded similar results to titles but also provided greater representation of specific research methods, such as "structural equation," "mixed method," "quasi-experimental," and "randomly assigned." Notably, all of these most popular methodological bigrams were either quantitative (e.g., "structural equation") or had a quantitative component (e.g., "mixed methods"), suggesting that the research literature in these journals is largely quantitative or that qualitative methodological identifiers (e.g., "grounded theory", "phenomenology") are more varied or less likely to be mentioned in abstracts.

Because the word stem "learn" (and specifically the full word "learning") was found to be the most common word in both titles and abstracts, we then constructed a series of word trees showing its common relationship to other words (excluding stopwords) for both the 2001-2010 and 2011-2020 timeframe (see Figs. 5 and 6). These word trees showed that "learning" was most often used in contexts like "online learning," "collaborative learning," "language learning," "learning environment," "learning performance," and "learning management." Comparing the two timeframes showed subtle changes between the decades, with "self-regulated" and "game-based learning" becoming more common and emphasis increasing on "learning management" and "performance" in later years.

Because "online" was the most common co-occurring word with "learning," and because of its relative importance during 2020 with the shifts resulting from COVID-19, we also constructed word trees showing its common relationships to other words for 2001-2010 and 2011-2020 (see Figs. 7 and 8). These word trees showed that "online" was most often used in contexts like "open online," "multiplayer online," "learning online," "online learning," "online course," and "online social." Comparing the two timeframes showed subtle 
Table 5 Top 15 Most Common Hyperlinked Domains in the Twitter \#EdTech Affinity Space in 2020

\begin{tabular}{lllll}
\hline Domain & Total Users & Percent of Users & Total Tweets & Percent of Tweets \\
\hline edsurge.com & 2927 & $11.9 \%$ & 6575 & $5.0 \%$ \\
youtu.be & 520 & $2.1 \%$ & 1893 & $1.4 \%$ \\
paper.li & 405 & $1.6 \%$ & 1633 & $1.2 \%$ \\
lnkd.in & 252 & $1.0 \%$ & 380 & $0.3 \%$ \\
shakeuplearning.com & 217 & $0.9 \%$ & 1452 & $1.1 \%$ \\
edtechmagazine.com & 136 & $0.6 \%$ & 482 & $0.4 \%$ \\
edutopia.org & 131 & $0.5 \%$ & 362 & $0.3 \%$ \\
forbes.com & 130 & $0.5 \%$ & 177 & $0.1 \%$ \\
linkedin.com & 122 & $0.5 \%$ & 206 & $0.2 \%$ \\
techcrunch.com & 114 & $0.5 \%$ & 155 & $0.1 \%$ \\
action.cosn.org & 106 & $0.4 \%$ & 117 & $0.1 \%$ \\
instagram.com & 81 & $0.3 \%$ & 104 & $0.1 \%$ \\
yourstory.com & 81 & $0.3 \%$ & 306 & $0.2 \%$ \\
nytimes.com & 80 & $0.3 \%$ & 220 & $0.2 \%$ \\
medium.com & 78 & $0.3 \%$ & 104 & $0.1 \%$ \\
\hline
\end{tabular}

changes between the two decades, with "open" and "social" contexts of "online" jumping to the top of the list.

As with the analysis of the Facebook data, we also used keyword searches for each of Weller's (2020) identified technologies and topics against article abstracts to determine their prevalence in the research literature (see Table 8). Generally speaking, most identified items saw a sizable uptick in representation in the years following Weller's identified year-

Table 6 Top 15 Most Common Words in Educational Technology Research Article Titles by Year

\begin{tabular}{lllllll}
\hline Stem & 2000 & 2005 & 2010 & 2015 & 2020 & Total \\
\hline learn* & $37.6 \%$ & $34.3 \%$ & $37.0 \%$ & $27.3 \%$ & $38.2 \%$ & $32.4 \%$ \\
student* & $11.3 \%$ & $11.6 \%$ & $21.4 \%$ & $18.1 \%$ & $20.7 \%$ & $17.7 \%$ \\
education* & $20.3 \%$ & $16.0 \%$ & $17.1 \%$ & $14.1 \%$ & $17.5 \%$ & $14.1 \%$ \\
online & $7.5 \%$ & $15.2 \%$ & $12.1 \%$ & $12.1 \%$ & $13.0 \%$ & $13.5 \%$ \\
based & $9.0 \%$ & $12.0 \%$ & $11.1 \%$ & $9.6 \%$ & $10.3 \%$ & $10.5 \%$ \\
use* & $4.5 \%$ & $6.8 \%$ & $7.3 \%$ & $8.0 \%$ & $6.8 \%$ & $8.4 \%$ \\
effect* & $1.5 \%$ & $4.2 \%$ & $4.6 \%$ & $8.0 \%$ & $8.8 \%$ & $7.8 \%$ \\
technology & $8.3 \%$ & $8.8 \%$ & $10.3 \%$ & $5.8 \%$ & $7.3 \%$ & $7.6 \%$ \\
social & $1.5 \%$ & $1.6 \%$ & $4.3 \%$ & $8.5 \%$ & $7.0 \%$ & $7.3 \%$ \\
teach* & $9.0 \%$ & $6.6 \%$ & $8.4 \%$ & $7.0 \%$ & $7.9 \%$ & $7.3 \%$ \\
environment* & $4.5 \%$ & $9.4 \%$ & $8.1 \%$ & $6.2 \%$ & $5.6 \%$ & $6.5 \%$ \\
design* & $4.5 \%$ & $9.4 \%$ & $7.4 \%$ & $5.1 \%$ & $7.4 \%$ & $6.4 \%$ \\
comput* & $7.5 \%$ & $10.2 \%$ & $8.5 \%$ & $5.4 \%$ & $3.5 \%$ & $6.0 \%$ \\
school* & $3.0 \%$ & $5.2 \%$ & $6.7 \%$ & $6.6 \%$ & $5.6 \%$ & $5.2 \%$ \\
system* & $6.0 \%$ & $6.4 \%$ & $7.0 \%$ & $4.4 \%$ & $4.5 \%$ & $5.2 \%$ \\
\hline
\end{tabular}

Note. Asterisks indicate that the term could be identified with any ending. For example, learn* would identify the inclusion of learns, learning, and learned suggesting a slight delay between when a technology or topic had come on the educational technology scene and when it became represented in the literature. However, a few notable exceptions to this pattern included blockchain, open textbooks, personal learning environments, connectivism, and elearning standards, as all of these topics seemed to remain rarely represented in the literature. This might reflect the difference between the permeation of an idea versus its suitability

Table 7 Top 15 Most Common Bigrams in Educational Technology Research Article Titles by Year

\begin{tabular}{lllllll}
\hline Stem & 2000 & 2005 & 2010 & 2015 & 2020 & Total \\
\hline high*+education* & $2.3 \%$ & $3.8 \%$ & $3.4 \%$ & $2.6 \%$ & $4.0 \%$ & $2.9 \%$ \\
learn*+environment* & $3.0 \%$ & $5.8 \%$ & $3.6 \%$ & $2.6 \%$ & $2.4 \%$ & $2.8 \%$ \\
based+learn* & $1.5 \%$ & $1.8 \%$ & $2.4 \%$ & $1.4 \%$ & $1.9 \%$ & $1.9 \%$ \\
online+learn* & $0.0 \%$ & $3.4 \%$ & $1.2 \%$ & $1.1 \%$ & $2.4 \%$ & $1.8 \%$ \\
social+network* & $0.0 \%$ & $0.0 \%$ & $0.9 \%$ & $2.5 \%$ & $1.0 \%$ & $1.7 \%$ \\
web*+based & $4.5 \%$ & $2.2 \%$ & $2.5 \%$ & $0.9 \%$ & $0.4 \%$ & $1.7 \%$ \\
social+media* & $0.0 \%$ & $0.0 \%$ & $0.0 \%$ & $1.7 \%$ & $2.3 \%$ & $1.5 \%$ \\
collaborative+learn* & $3.8 \%$ & $2.8 \%$ & $1.5 \%$ & $2.1 \%$ & $0.8 \%$ & $1.3 \%$ \\
school*+student* & $0.0 \%$ & $0.0 \%$ & $1.6 \%$ & $1.5 \%$ & $1.2 \%$ & $1.2 \%$ \\
problem*+solving & $0.0 \%$ & $1.0 \%$ & $1.1 \%$ & $1.0 \%$ & $1.3 \%$ & $1.1 \%$ \\
distance+education* & $6.0 \%$ & $3.0 \%$ & $2.3 \%$ & $0.8 \%$ & $0.8 \%$ & $1.1 \%$ \\
pre+service & $0.8 \%$ & $0.4 \%$ & $1.3 \%$ & $1.4 \%$ & $1.2 \%$ & $1.0 \%$ \\
language+learn* & $0.8 \%$ & $1.2 \%$ & $1.0 \%$ & $0.9 \%$ & $1.4 \%$ & $1.0 \%$ \\
high*+school* & $0.0 \%$ & $0.2 \%$ & $1.3 \%$ & $0.9 \%$ & $1.2 \%$ & $1.0 \%$ \\
university+student* & $0.0 \%$ & $0.4 \%$ & $0.9 \%$ & $1.3 \%$ & $1.1 \%$ & $0.9 \%$ \\
\hline
\end{tabular}

Note. Asterisks indicate that the term could be identified with any ending. For example, "high* + education*" would identify the inclusion of "higher education" and "higher educational" 


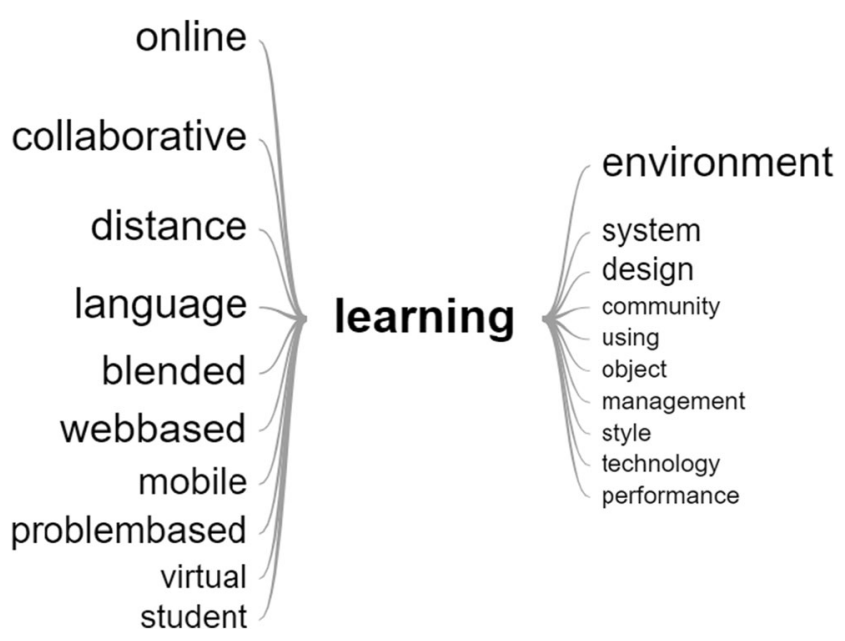

Fig. 5 Word Tree for "Learning" in 2001-2010 Titles

as a topic of targeted empirical study, as in the case of connectivism, but it also might represent simple delays between practice and research, as in the case of blogs and wikis, which did not see a sizable increase in article representation until 5-10 years after Weller's identification. Such a lag might explain lack of blockchain research (given its relative infancy), but there do seem to be some technologies and topics that have been of interest in educational technology for 7+ years that still remain largely underrepresented in the literature, such as e-learning standards, open textbooks, and personal learning environments.

From these analyses of Scopus-provided research articles, we conclude that (a) online learning remains preeminent as the most-researched area in educational technology, (b) the past decade has seen a shift to connecting this to tools and activities that are more "open" and "social," and (c) there seems to remain a lag or disconnect between technologies that are actually being used in educational institutions and the research base supporting or guiding their use (cf., Kimmons 2020), with some topics not being taken up by researchers practically at all.

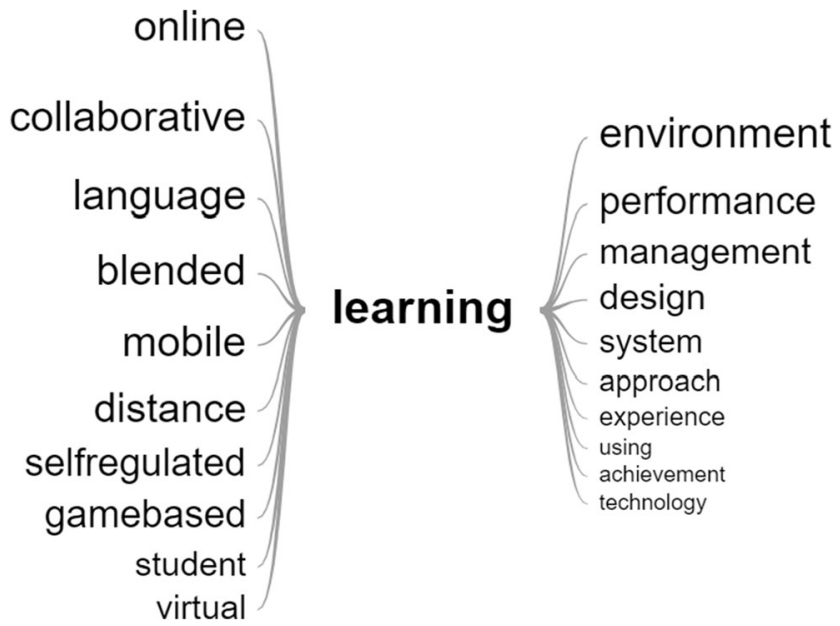

Fig. 6 Word Tree for "Learning" in 2011-2020 Titles

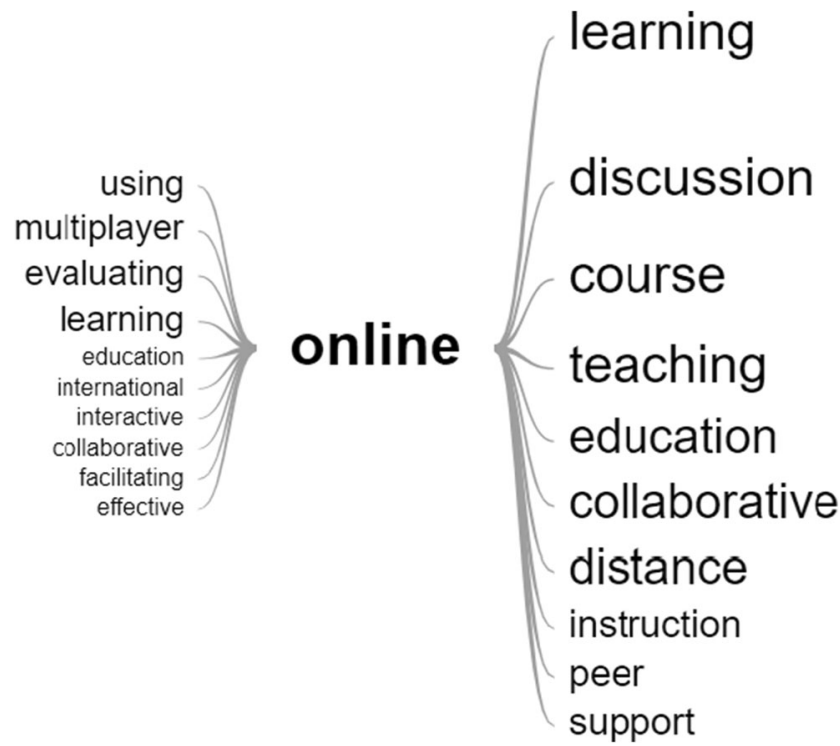

Fig. 7 Word Tree for "Online" in 2001-2010 Titles

\section{Summary and Looking Ahead}

In addition to offering insights into educational technology behaviors and trends, these analyses offer a mirror for the educational technology field itself in a few key areas. First, one of the more subtle findings from the Scopus dataset indicates positivist or quantitative preferences and tendencies in methodological choices, suggesting limited methodological pluralism (Kimmons and Johnstun 2019). Indeed, this is not a new finding (e.g., Carr-Chellman and Carr-Chellman 2020 and the 2020/5 systems thinking and change special issue of TechTrends), yet, it is one that requires careful consideration and the possible need for adjusting the field's overall philosophical orientation. Our selection and array of methods should mirror the complexity of issues, phenomena, and

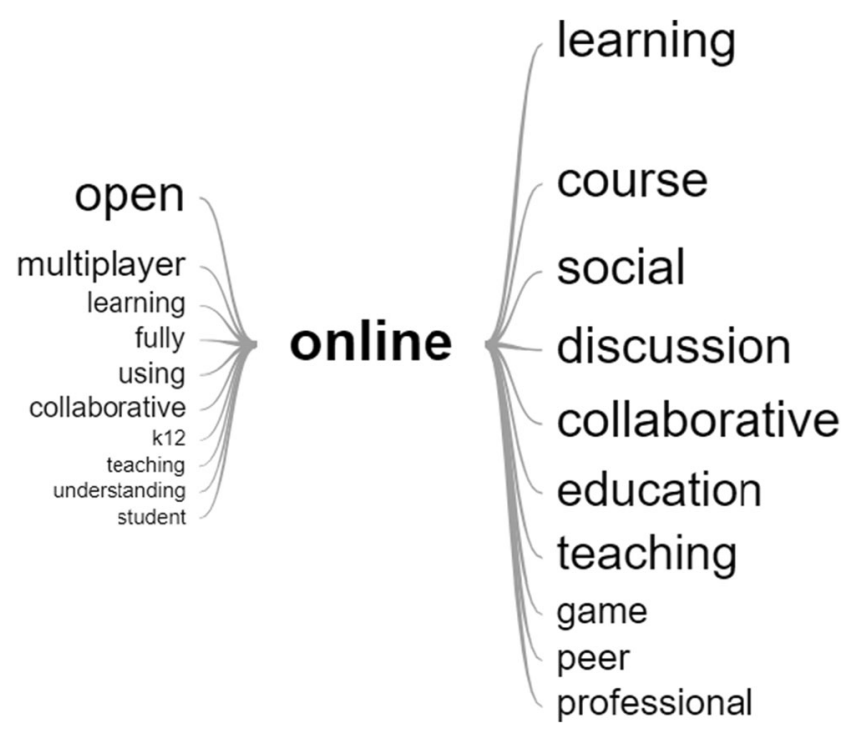

Fig. 8 Word Tree for "Online" in 2011-2020 Titles 
要|

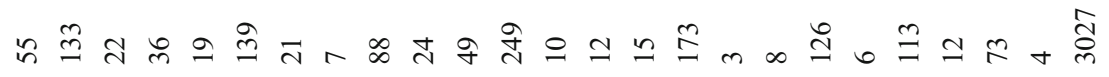

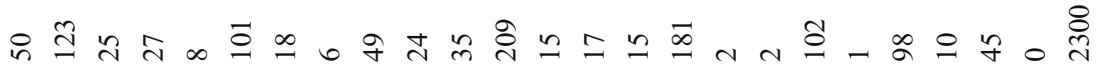
요

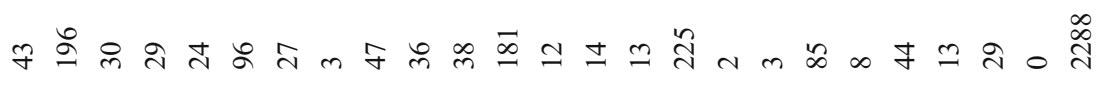

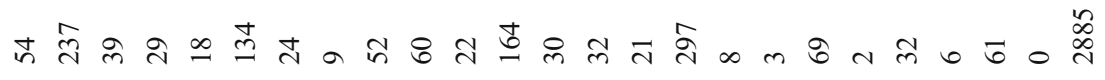
ஸे ते ते 흘 융 毒

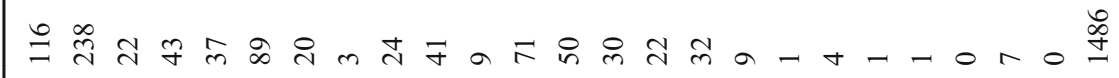

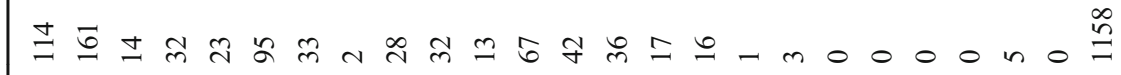
ปิ $\cong$ ส

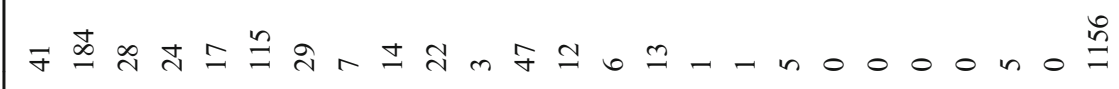

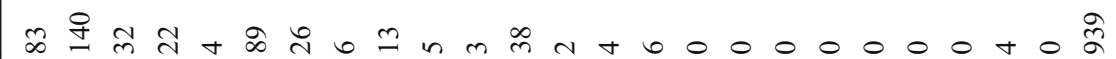

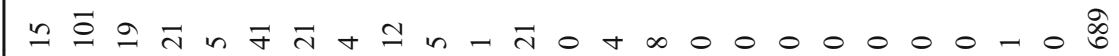

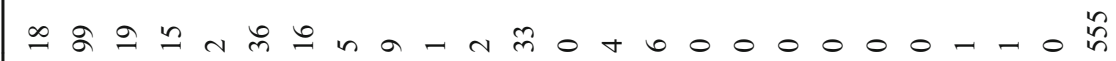

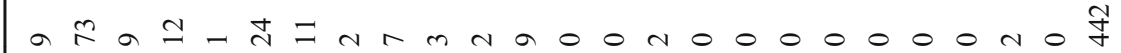

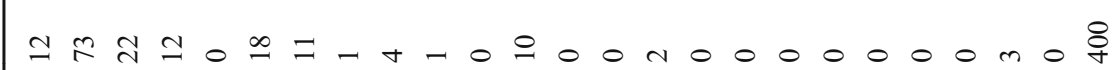
z + Ba에 $m-n 00 m 0000000000-0$ m

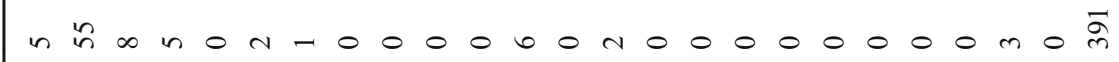

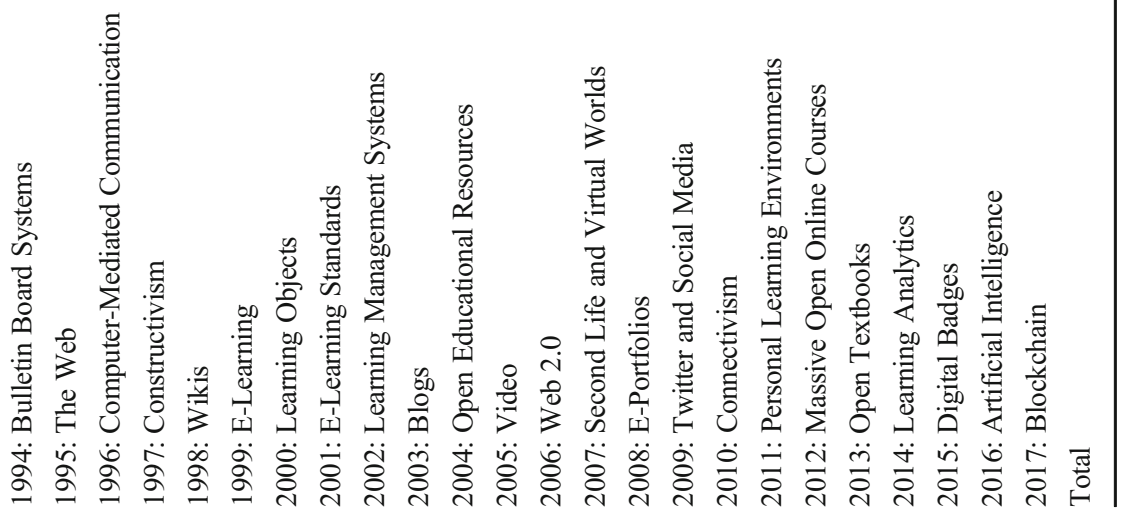


questions found in our field. As we examine human behaviors related to learning, teaching, and development of thought and language, we need methodologies and research designs that are sensitive to these complex and dynamic realities. In addition, we need a rich array of research methods that would better allow us to see these complicated patterns and make new connections, as well as, confront the demanding issues of causality and generalizability in more sophisticated and nuanced ways. The analysis of public data presented in this article is one example of a technique that can be brought to bear on emergent educational problems, but if the problems we face in educational technology are complex, situated, and diverse, then our research methods should reflect this broadly.

Second, the year 2020 brought about many dramatic upheavals for societies and institutions, especially in response to COVID-19, and our results support the notion of responsive shifts and adjustments in educational technology, such as the rapid emphasis on "remote learning" in April. However, one of our takeaways from this analysis was that most changes in 2020 seemed to be changes of degree rather than kind and that in many ways the educational technology field was already trending in directions that seemed to be necessary for addressing the pandemic before it started. Some examples of this include the following findings from this study:

- social media had been gradually adopted by schools and used as a rapid communication platform with parents and community members leading up to 2020 ;

- much of the research literature prior to 2020 had focused on topics that were necessary for enacting technology-mediated, socially-distant teaching;

- and, many schools, teachers, and education leaders were already using existing tools necessary for socially-distant teaching and connectedness prior to 2020 in key ways for improving productivity and sharing valuable practices, resources, and expertise.

We do not point this out to minimize the difficulties or immense tolls that the pandemic exacted upon students, parents, educators, and institutions, but it does seem clear that our collective abilities to respond to and cope with the pandemic would likely have been even far more strained if these tools, practices, and research topics had not been so firmly in place, to begin with. That is, though we as scholars and academics generally feel far more comfortable and safe heaping criticisms upon and deconstructing existing systems than we do in praising what has come before, we should acknowledge that educators' and institutions' heroic responses to the pandemic were at least partially made possible or supported by the groundwork that the educational technology community established in prior years. So, for that, we should be grateful and pleased.

And third, though the long-term impacts of the pandemic on our students and our institutions are still poorly understood
(Kuhfeld et al. 2020), it at least seems that we have been moving in some good directions and that problems and difficulties in our educational institutions that were laid bare by the pandemic can now be taken up with renewed effort, focus, and hope that we can realistically conquer them. Perhaps the most glaring inadequacies that we must continue to address in educational technology revolve around issues of inequity, practicality, scalability, sustainability, privacy, and dissemination. Notably, many of the benefits provided by the groundwork noted above are dependent upon individual educators' and institutions' existing social capital, networks, and literacies (Veletsianos and Kimmons 2012). Also, though much research may have already been done on the topics that were needed to address the challenges of the pandemic, whether such studies were sufficiently accessible, practical, or situated in authentic contexts to realistically be of help to struggling schools and educators is another matter (Reeves and Lin 2020). Indeed, the ability to benefit from existing work and research in our field may largely depend upon local social capital and economic resources and will therefore require close partnerships with educators and youth and their families moving forward (Greenberg et al. 2020). This is especially true in the cases of marginalized, underserved, and disenfranchised communities.

This is especially important to recognize as current trends in the U.S. and elsewhere may be leading to increased segregation and disparities based on race, income, and other factors (Orfield and Frankenberg 2014), and COVID-19, in particular, seems to be amplifying a variety of inequities related to educational access, economic security, and health care (Fortuna et al. 2020). In this context, we note that inequity was not a theme strongly represented in our analyses. This may reflect both the focus of the research journals and the nature of the communities included in our analyses. Therefore, as we consider how well-prepared practitioners were for this past year, we must do so with persistent educational inequities in mind and move forward in ways that seek to improve learning for all.

In our estimation, some of the ways this analysis might look different if our field was fully committed to addressing both the problems of today and tomorrow would include the following. First, we would see more situated work in practical contexts working with educators to address local problems and to communicate these solutions in ways that are transferable to other contexts. Second, we would see more focus on providing learning and professional development opportunities to all students and teachers via free and open formats, including open educational resources, open textbooks, and open pedagogies (and do research on these activities). Third, we would care less about the newest, expensive gadgets and focus more of our attention on the underlying pedagogical, access, and equity issues governing their use. And fourth, we would further eschew easy, silver-bullet answers to pernicious education problems and embrace the complexity, 
messiness, and situatedness of the work we do, while simultaneously helping policy- and decision-makers to do the same. Making such adjustments to our field requires concerted effort, but if 2020 has taught us anything about the people working in our field, we should acknowledge that change is constant and that our professionals are resilient and capable, even in the face of heretofore unimaginable crises.

\section{References}

Bodily, R., Leary, H., \& West, R. E. (2019). Research trends in instructional design and technology journals. British Journal of Educational Technology, 50(1), 64-79.

Carpenter, J., Kimmons, R., Short, C., Clements, K., \& Staples, M. E. (2019). Teacher identity and crossing the professional-personal divide on twitter. Teaching and Teacher Education, 81, 1-12. https:// doi.org/10.1016/j.tate.2019.01.011.

Carr-Chellman, D. J., \& Carr-Chellman, A. (2020). Integrating systems: The history of systems from von Bertalanffy to profound learning. TechTrends, 64(5), 704-709.

CrowdTangle Team. (2020). About us: Learn more about CrowdTangle. CrowdTangle. https://help.crowdtangle.com/en/articles/4201940about-us.

Dwivedi, Y. K., Hughes, D. L., Coombs, C., Constantiou, I., Duan, Y., Edwards, J. S., et al. (2020). Impact of COVID-19 pandemic on information management research and practice: Transforming education, work and life. International Journal of Information Management, 55, 102211.

Fortuna, L. R., Tolou-Shams, M., Robles-Ramamurthy, B., \& Porche, M. V. (2020). Inequity and the disproportionate impact of COVID-19 on communities of color in the United States: The need for a traumainformed social justice response. Psychological Trauma: Theory, Research, Practice, and Policy, 12(5), 443-445.

Gee, J. P. (2004). Situated language and learning: A critique of traditional schooling. Psychology Press.

Greenberg, D., Calabrese Barton, A., Turner, C., Hardy, K., Roper, A., Williams, C., et al. (2020). Community infrastructuring as necessary ingenuity in the COVID-19 pandemic. Educational Researcher, 49(7), 518-523.

Hodges, C., Moore, S., Lockee, B., Trust, T., \& Bond, A. (2020). The difference between emergency remote teaching and online learning. Educause Review, 27, 1-12.

Keyes, O., Jacobs, J., Schmidt, D., Greenaway, M., Rudis, B., Pinto, A., Khezrzadeh, M., Meilstrup, P. Costello, A. M., Bezanson, J., Meilstrup, P., \& Jiang, X. (2019). Urltools: Vectorised tools for URL handling and parsing. R-Project. https://cran.r-project.org/ web/packages/urltools/index.html.

Kimmons, R. (2020). Current trends (and missing links) in educational technology research and practice. TechTrends, 64(6). https://doi.org/ 10.1007/s11528-020-00549-6.

Kimmons, R., Carpenter, J., Veletsianos, G., \& Krutka, D. (2018). Mining social media divides: An analysis of K-12 U.S. school uses of twitter. Learning, Media, \& Technology, 43(3), 307-325. https:// doi.org/10.1080/17439884.2018.1504791.

Kimmons, R., Hunsaker, E., Jones, J. E., \& Stauffer, M. (2019). The nationwide landscape of K-12 school websites in the United States: Systems, services, intended audiences, and adoption patterns.
The International Review of Research in Open and Distributed Learning, 20(3). Doi:https://doi.org/10.19173/irrodl.v20i4.3794.

Kimmons, R., \& Johnstun, K. (2019). Navigating paradigms in educational technology. TechTrends, 63(5), 631-641. https://doi.org/10. 1007/s11528-019-00407-0.

Kimmons, R., \& Veletsianos, G. (2018). Public internet data mining methods in instructional design, educational technology, and online learning research. TechTrends, 62(5), 492-500. https://doi.org/10. 1007/s11528-018-0307-4.

Kuhfeld, M., Soland, J., Tarasawa, B., Johnson, A., Ruzek, E., \& Liu, J. (2020). Projecting the potential impact of COVID-19 school closures on academic achievement. Educational Researcher, 49(8), 549-565.

Lin, T. J., Lin, T. C., Potvin, P., \& Tsai, C. C. (2019). Research trends in science education from 2013 to 2017: A systematic content analysis of publications in selected journals. International Journal of Science Education, 41(3), 367-387. https://doi.org/10.1080/09500693. 2018.1550274 .

Mockus, A., Fielding, R. T., \& Herbsleb, J. D. (2002). Two case studies of open source software development: Apache and Mozilla. ACM Transactions on Software Engineering and Methodology, 11(3) Retrieved from https://dl.acm.org/doi/abs/10.1145/567793.567795.

National Center for Education Statistics. (2019). Elementary/secondary information system. National Center for Education Statistics. Retrieved from https://nces.ed.gov/ccd/elsi/default.aspx?agree $=0$

Orfield, G., \& Frankenberg, E. (2014). Increasingly segregated and unequal schools as courts reverse policy. Educational Administration Quarterly, 50(5), 718-734.

Perrin, A., \& Anderson, M. (2019). Share of U.S. adults using social media, including Facebook, is mostly unchanged since 2018. Pew Research Center. Retrieved from https://www.pewresearch.org/ fact-tank/2019/04/10/share-of-u-s-adults-using-social-mediaincluding-facebook-is-mostly-unchanged-since-2018/

$\mathrm{R}$ Core Team. (2021). The R project for statistical computing. R-Project. https://r-project.org.

Reeves, T. C., \& Lin, L. (2020). The research we have is not the research we need. Educational Technology Research and Development, 68(4), 1991-2001.

Trust, T., Carpenter, J., Krutka, D. G., \& Kimmons, R. (2020). \#RemoteTeaching \& \#RemoteLearning: Educator tweeting during the COVID-19 pandemic. Journal of Technology and Teacher Education, 28(2), 151-159.

Trust, T., Krutka, D. G., \& Carpenter, J. P. (2016). "Together we are better": Professional learning networks for teachers. Computers \& Education, 102, 15-34.

van Mierlo, T. (2014). The $1 \%$ rule in four digital health social networks: An observational study. Journal of Medical Internet Research, 16(2), e33.

Veletsianos, G., \& Kimmons, R. (2012). Assumptions and challenges of open scholarship. The International Review of Research in Open and Distributed Learning, 13(4), 166-189.

Veletsianos, G., \& Kimmons, R. (2016). Scholars in an increasingly digital and open world: How do education professors and students use twitter? The Internet and Higher Education, 30, 1-10. https:// doi.org/10.1016/j.iheduc.2016.02.002.

Weller, M. (2020). 25 years of ed tech. Athabasca University Press.

Williamson, B., Eynon, R., \& Potter, J. (2020). Pandemic politics, pedagogies and practices: Digital technologies and distance education during the coronavirus emergency. Learning, Media and Technology, 45(2), 107-114. https://doi.org/10.1080/17439884. 2020.1761641

Publisher's Note Springer Nature remains neutral with regard to jurisdictional claims in published maps and institutional affiliations. 